\title{
64. Proparian Genus of the Olenidae and its bearing on the Trilobite Classification.
}

\author{
By Teiichi KobaYashi.
}

(Comm. by H. YABE, M.I.A., June 12, 1936.)

Radical changes have appeared on the tripartite divisions of Trilobita since its establishment by Beecher some forty years ago. Swinnerton neglected Hypoparia because of its heterogenity, while Richter regarded Proparia as being more primitive than Opisthoparia. At the time of Beecher, Proparian trilobites were confined to the Ordovician and later eras. Subsequent researches, however, have revealed several Proparian trilobites, such as Pagetia, Norwoodia and so forth in the Cambrian faunae.

In revising the list of Proparian or Proparian-like trilobites $\mathrm{I}^{1)}$ have arrived at the conclusion that Proparia is also a heterogenous aggregate, as so considered by $\mathrm{Raw},{ }^{2)}$ and that the Proparian tendency appears in the later stages of certain evolutional lines.

Subsequently, I had the opportunity of studying a Proparian Olenidae, i. e., Jujuyaspis from Jujuy, Argentina." ${ }^{3}$ It was represented by a unique species, $J$. keideli, having no genal spine. This defect did not permit the determination of whether or not it was a Proparian trilobite in Beecher's sense.

I found in Steinmann and Hoek's collection $^{4)}$ from South America another species, J. steinmanni (nov.) provided
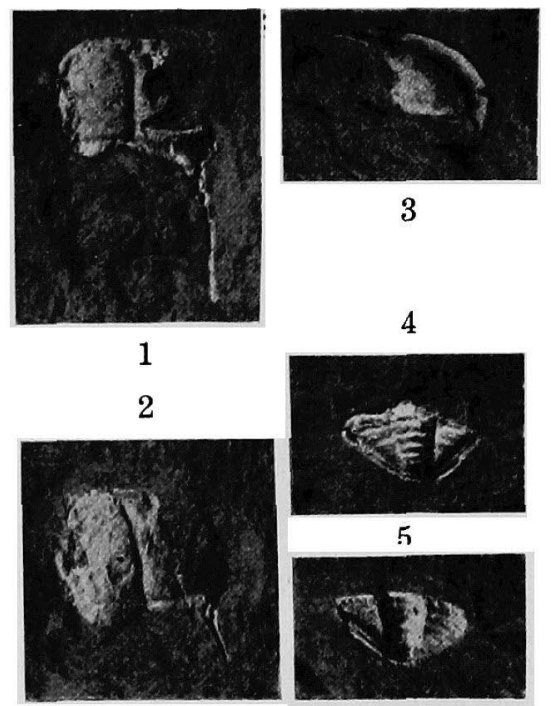

3

4

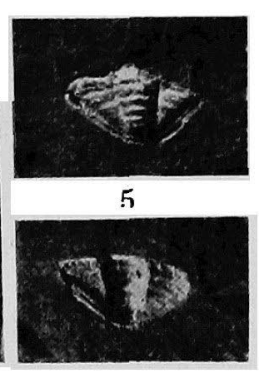
with a genal spine on the fixed cheek; thus, the ambiguity was clearly settled.

As discussed elsewhere, ${ }^{3)}$ Jujuyaspis has the combined character-

1) Teiichi Kobayashi (1935), The Cambro-Ordovician Formations and Faunas of South Chosen, Palaeontology, Pt. 3, Cambrian Faunas of South Chosen with a special study of the Cambrian Trilobite Genera and Families, Jour. Fac. Sci. Imp. Univ. Tokyo, Sec. 2, Vol. 4, Pt. 2, pp. 76-95.

Since the appearance of this work, C. Lochman established a Proparian genus, Avonia, from the Upper Cambrian of Missouri, Jour. Palaeont., Vol. 10, p. 42.

2) F. Raw (1925), Development of Leptoplastus salteri (Callaway) and of other Trilobites (Olenidae, Ptychoparidae, Conocoryphinidae, Paradoxidae, Phacopidae and Mesonacidae), Quart. Jour. Geol. Soc. London, Vol. 81, p. 285.

3) T. Kobayashi (1936), On the Parabolinella Fauna from the Province Jujuy, Argentina with a Note on the Olenidae, Japan Jour. Geol. \& Geogr., Vol. 13, p. 89.

4) I wish to thank Prof. W. Soergel, of the Geological Institute of Freiburg $i$. $\mathrm{Br}$., Germany, for the privilege of describing this interesting trilobite. The complete results of my revision of Steinmann and Hoek's Cambro-Ordovician collections of South America will be published in another paper. 
istics of Sphaerophthalmus and Leptoplastus, except for its Proparian nature. Therefore I regard it as a member of the Leptoplastinae. It is either latest Upper Cambrian or earliest Tremadocian in age, since $J$. keideli is accompanied by Parabolinella argentinensis. Thus, I believe that Jujuyaspis can be taken for the last representative of that subfamily with which this evolutional branch apparently died out. In other words, it has little phylogenetic relationship with the later proparian genera or with other Cambrian ones. The discovery of Jujuyaspis, therefore, substantiates my conclusion that Proparia is polyphyletic.

It is questionable whether there is a certain all-encompassing rule, other than the facial suture, which would apply to a classification of all trilobites. It seems to me that a combination of all the characteristics would be more important than any single characteristic of the facial suture. Therefore, unless the morphological array based on these characters is checked by the ontogeny and geological and geographical distributions, the phylogeny of the trilobites can hardly be securely established.

Since the genus and genotype have already been described, only the specific distinctions of $J$. steinmanni from J. keideli are given below:

1) The glabella is narrower in J. steinmanni than in the latter; anterior margin of cephalon more or less sinuated in the latter whereas straight in the former.

2) The position of the eye is more anterior in $J$. steinmanni than in the other.

3) The facial suture behind the eye

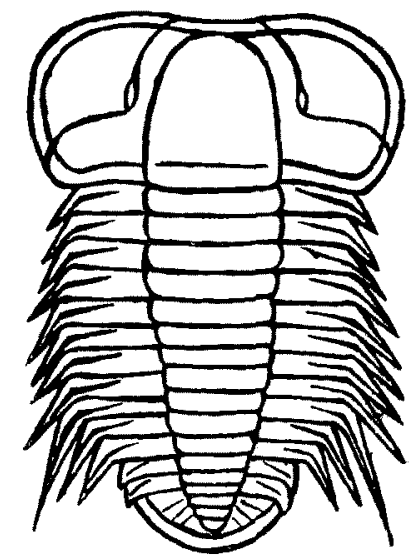

6 crosses the cheek in a rather oblique direction in $J$. steinmanni, while it is almost transversal in $J$. keideli.

4) The fixed cheek in $J$. steinmanni has a genal spine.

The cranidium, free cheek, thoracic segment and pygidium of $J$. steinmanni are all known, but detached from one another. All parts of the carapace reveal a marvelous similarity to those of $J$. keideli except for the several minor distinctions enumerated above. Practically no distinction can be seen in the pygidia of both species.

\section{Explanation of Text-Figures.}

Jujuyaspis steinmanni Kobayashi, sp. nov.

Figs. 1-2. Cranidia, Fig. 3, free cheek, Figs. 4-5, Pygidia.

All $\times 1.5$.

Loc. Guanacuno, Bolivia.

Jujuyaspis keideli Kobayashi.

Fig. 6, Reconstruction. See figs. 5-9, pl. 16, in Japan. Jour. Geol. a. Geogr., Vol. 13, 1936. 